\title{
Determination of Ethyl Carbamate in Commercial Sweetened Sugar Cane Spirit by ESI-MS/MS Using Modified QuEChERS and 18-Crown-6/Trifluoroacetic Acid Spiking Additives
}

\author{
Angélica P. P. Tonin, ${ }^{a}$ Camila B. Poliseli, ${ }^{b}$ Nayane M. Sinosaki, ${ }^{a}$ Fernanda C. Martinez, ${ }^{b}$ \\ Oscar O. Santos, ${ }^{\circledR a}$ Cláudio C. Oliveira, ${ }^{a}$ Valquiria M. Silva, ${ }^{b}$ Jesuí V. Visentainer ${ }^{\circledR a}$ and \\ Eduardo C. Meurer ${ }^{\circledR} *, a, b$
}

${ }^{a}$ Departamento de Química, Universidade Estadual de Maringá (UEM), Av. Colombo, 5790, 87020-900 Maringá-PR, Brazil

${ }^{b}$ Universidade Federal do Paraná (UFPR), Campus Avançado Jandaia do Sul, 86900-000 Jandaia do Sul-PR, Brazil

\begin{abstract}
A fast, sensitive, and selective direct injection electrospray tandem mass spectrometry (DI-ESI-MS/MS) method that is able to quantify ethyl carbamate in commercial sweetened sugar cane spirit is described. The preparation method uses a modified QuEChERS (quick, easy, cheap, effective, rugged, and safe) with potassium carbonate added to sweetened sugar cane spirit to separate the aqueous phase from the ethanol phase. The aqueous phase contains sucrose that suppresses electrospray ionization. Ethyl carbamate supernatant from the ethanol phase is transferred and enriched with 18-crown-6/trifluoroacetic acid additives. The additives sequester metal cations reducing the ionization of sodium and potassium, favoring the detection of ethyl carbamate as sole protonated cations. The method was successfully applied for the quantification of eleven real samples and certified sugar cane spirit demonstrating its applicability for quality control and regulatory analysis. The method showed reliable analytical parameters compared to conventional gas chromatography mass spectrometry (GC-MS) method commonly used for ethyl carbamate analysis. DI-ESI-MS/MS method requires just a fast step sample clean up and presents consistent values for the limit of detection (LOD $48.0 \mu \mathrm{g} \mathrm{L}^{-1}$ ) and limit of quantification (LOQ $160.0 \mu \mathrm{g} \mathrm{L}^{-1}$ ). Furthermore, the recoveries obtained were close to $100 \%$, with relative standard deviations below $10 \%$ of sample certificates.
\end{abstract}

Keywords: sweetened sugar cane spirit, modified QuEChERS, ethyl carbamate, tandem mass spectrometry, sugar matrix effect

\section{Introduction}

Cachaça is a type of sugar cane spirit produced in Brazil and recognized as a typical Brazilian alcoholic drink that might be sweetened or not with sucrose. The Ministry of Agriculture, Livestock and Supply (MAPA) ${ }^{1}$ from Brazil has stated sugar cane spirit and cachaça as alcoholic drinks from 38 to $54 \%$, and 38 to $48 \%$ of ethanol levels (v/v) at $293 \mathrm{~K}$, respectively, which may be added $6 \mathrm{~g} \mathrm{~L}^{-1}$ of sucrose; sweetened cachaça or sweetened sugar cane spirit may contain until $30 \mathrm{~g} \mathrm{~L}^{-1}$ of sucrose. ${ }^{2}$ There are a variety of deleterious compounds in cachaça and sugar cane spirit

*e-mail: eduardo.meurer@ufpr.br

Editor handled this article: Emanuel Carrilho (Associate) that might be evaluated as quality control parameters to assure the safety of the alcoholic drink, such as polycyclic aromatic hydrocarbons, ${ }^{3}$ furfural, ${ }^{4}$ methanol, ${ }^{4}$ and copper, ${ }^{5}$ among them ethyl carbamate takes a relevant place since it was found to be carcinogenic. ${ }^{1}$

Ethyl carbamate (PubChem CID 5641) is formed in food and beverages by the reaction of ethanol with hydrogen cyanide, ${ }^{6}$ and may be formed in the process of producing cachaças and sugar cane spirits. ${ }^{7-10}$ Sugar cane spirits are very popular in Brazil, specifically cachaça, and are part of a typical drink called "caipirinha" (a mixture of cachaça or sugar cane spirit to sugar, lemon and ice). In Brazil, the maximum residue level of ethyl carbamate in (sweetened or not) cachaça and sugar cane spirit is $210 \mu \mathrm{g} \mathrm{L}^{-1}$, as defined by MAPA, the Brazilian regulation agency for food control. ${ }^{1}$ 
Direct injection electrospray mass spectrometry (DI-ESI-MS/MS) is an efficient analytical technique, ${ }^{11}$ even though the electrospray ionization (ESI) technique is made for polar organic molecules analysis, it suffers from a strong matrix effect for qualitative and quantitative experiments. ${ }^{12-17}$ Despite the matrix effect, if controlled, useful methods using DI-ESI-MS/MS have been presented and have been successfully applied to a variety of matrices and analytes. Some methods related to direct injection to mass spectrometry such as determination of glyphosate and aminomethylphosphonic acid in water samples ${ }^{18}$ refer to direct injection to the fact that almost no sample preparation was achieved on the methodology. The direct flow injection mass spectrometry should meet the criteria for the absence of chromatography, and some recent methods meet these criteria such as the analysis of acylglycerols from food products with direct flow injection profiling using isopropanol as the solvent. ${ }^{19}$ Another recent paper using direct flow analyzes of proteins with tandem mass spectrometry showed good limits of detection with supercharged proteins. ${ }^{20}$ The use of direct injection in electrospray triple quadrupole mass spectrometer to determine tropane alkaloids in cereal based baby foods was achieved avoiding chromatographic step. ${ }^{21}$

Analyzes of ethyl carbamate in alcoholic drinks are a major concern by regulatory agencies. To improve the confidence of analyzes a certified reference material of ethyl carbamate in the hydroalcoholic matrix was developed and analyzed using isotopic dilution gas chromatographymass spectrometry and could improve quality control in industry. ${ }^{22}$ Another research used the determination of ethyl carbamate in sugar cane spirit with high-performance liquid chromatography (HPLC) with fluorescence detection (FLD) and was found to be effective. ${ }^{23}$ Since sugar cane spirit represents an important economic impact and is the most consumed beverage in Brazil, MAPA suggests using the gas chromatography tandem mass spectrometry (GC-MS/MS) method developed by Lachenmeier et al. ${ }^{24}$ as a reference method.

In previous work, ${ }^{25}$ a validated method for the determination of ethyl carbamate in sugar cane spirit by direct injection electrospray ionization tandem mass spectrometry using 18-crown-6/trifluoroacetic acid spiking additives, achieved accurate and exact results. Otherwise, the method was efficient only for sugar cane spirit, sweetened sugar cane spirit with sucrose until $30 \mathrm{~g} \mathrm{~L}^{-1}$ was tested and the results were not accurate since the high matrix effect was impeditive for the DI-ESI-MS/MS method. It was performed the sample preparation using modified QuEChERS (quick, easy, cheap, effective, rugged, and safe) method with sodium carbonate to reduce the matrix effect improving the robustness for matrices with sugar, external standard addition curves were constructed and the results used to compare with standard addition. ${ }^{26}$ The improved DI-ESI-MS/MS method was tested for eleven commercial sweetened cachaça and sugar cane spirit, two samples of sweetened cachaça analyzed in a certified laboratory using GC-MS technique, one cachaça, and one sugar cane spirit, illustrating its application to quality control and regulation analysis of real samples.

\section{Experimental}

\section{Materials and reagents}

Ethyl carbamate was purchased from Sigma-Aldrich (Saint Louis, USA). HPLC-grade methanol was obtained from Vetec-Sigma-Aldrich (Duque de Caxias, Brazil). Trifluoracetic acid and 18-crown-6 ether were purchased from Merck (Darmstadt, Germany). Water was obtained using a Milli-Q water purification system (Millipore, Bedford, MA, USA).

\section{Instrumentation}

The sample elution was conducted using methanol with $0.10 \%$ trifluoracetic acid (TFA) and $30 \mathrm{mg} \mathrm{L}^{-1}$ of 18-crown- 6 as a carrier solution at a flow-rate of $200 \mu \mathrm{L} \mathrm{min}{ }^{-1}$ set on an automatic pump. It was injected directly $5 \mu \mathrm{L}$ of the sample using a rheodyne of the mass spectrometer with a total run time of 2 min at room temperature. It was used a Quattro Premier XE (Waters, Milford, MA, USA) tandem quadrupole mass spectrometer with electrospray (ESI) source. Desolvation gas and source block temperatures were 250 and $110^{\circ} \mathrm{C}$, respectively. The electrospray source was operated (ESI+) at $3.5 \mathrm{kV}$ and the SRM (selected reaction monitoring) channel was set for $90>62$. The cone voltage, collision energy and collision gas pressure (argon) were $20 \mathrm{~V}, 12 \mathrm{~V}$, and $3.5 \times 10^{-3}$ Torr (all parameters were optimized and reached the same values of Ribeiro et al.). ${ }^{25}$

\section{Standards and sample preparation}

A stock solution of ethyl carbamate $\left(0.10 \mathrm{~g} \mathrm{~L}^{-1}\right)$ was prepared, dissolving $0.0100 \mathrm{~g}$ of the ethyl carbamate in $100 \mathrm{~mL}$ of methanol. The working solutions were diluted obtaining 1.5, 3.0, 6.0, 9.0, 12.0, 15.0 and $18.0 \mathrm{mg} \mathrm{L}^{-1}$.

The sweetened cachaças were submitted to the QuEChERS process modification to obtain two layers, the superior layer of ethanol and ethyl carbamate, and the inferior aqueous layer with sucrose and more polar 
compounds. The ethanolic layer was transferred and mixed with water to reconstruct the same proportion of the original cachaça. The spiked reconstructed cachaças without sugar were made using $50 \mu \mathrm{L}$ of each solution of ethyl carbamate in methanol to obtain concentrations of $75,150,300,450$, 600,750 , and $900 \mu \mathrm{g} \mathrm{L} \mathrm{L}^{-1}$ with $30 \mathrm{ppm}$ of 18-crown-6 and $0.1 \%$ of TFA. The samples were directly injected into the DI-ESI-MS/MS system. ${ }^{25,27}$

\section{Modified QuEChERS}

The original QuEChERS was modified to improve the separation of sugar and make it cheaper. To an aliquot of $20.0 \mathrm{~mL}$ of sweetened cachaça were added $10.0 \mathrm{~g}$ of potassium carbonate, and vortexed for $1 \mathrm{~min}$ to form two phases: aqueous phase with sugar and ethanolic phase rich in ethyl carbamate. After that, $5 \mathrm{~mL}$ of the organic supernatant layer, which contains the highest ethyl carbamate concentrations due to the greater solubility of ethyl carbamate in ethanol, ${ }^{26}$ was collected and mixed with Milli-Q water to reconstructed sugar-free cachaça.

\section{Matrix effect evaluation}

Matrix effect was evaluated by analyzing the same cachaça with no added sucrose (A) and with added sucrose (A'). In this case, we were able to notice that the use of QuEChERS did not change the results in relation to these validation parameters. In addition, the analysis of a sweetened cachaça without the application of the modified QuEChERS method was not performed, since carbohydrate analysis by ESI-MS is considered a difficult and laborious analysis. ${ }^{25,28}$

\section{Linearity for standard addition}

For the standard addition, ethyl carbamate was added directly to the samples (reconstructed cachaça without sugar, see "Modified QuEChERS" sub-section), and for the calibration curve was used the sample which presented the lowest real concentration of ethyl carbamate to spike the analytical curve (external calibration), and applied to all samples.

To evaluate the linearity, two methodologies were tested: standard addition and calibration curve. For both tests, analytical curves were constructed with seven levels of ethyl carbamate $(0,75,150,300,450,600,750$, and $\left.900 \mu \mathrm{g} \mathrm{L}^{-1}\right)$ in the reconstructed cachaça without sugar. It was plotted the peak area of the analyte versus the nominal concentrations and the least-squares regression analysis was applied to determine the equation of the curve obtained.

\section{Specificity and selectivity}

The specificity and selectivity of the method were tested through the analysis of fortified and non-fortified sweetened sugar cane spirits to evaluate possible interferences. ${ }^{29}$

Limit of detection (LOD) and limit of quantification (LOQ)

For the external calibration analysis, the limits of detection (LOD) and quantification (LOQ) were calculated based on the parameters estimated for the analytical curve: $\mathrm{LOD}+3.3 \times \mathrm{s} / \mathrm{S}$ and LOQ $=10 \times \mathrm{s} / \mathrm{S}$, where $(\mathrm{s})$ is the estimate of the standard deviation of the equation linear coefficient, and (S) is the angular coefficient of the analytical curve. ${ }^{30}$

\section{Accuracy}

The samples A of $240.0 \mu \mathrm{g} \mathrm{L}^{-1}$ (without sucrose) and A' $226.0 \mu \mathrm{g} \mathrm{L}^{-1}$ (with sucrose) of ethyl carbamate were analyzed in a certified laboratory (LANAGRO) using GC-MS technique and used for the intra- and inter-day precision and recovery test. Sample A is the sugar cane spirit (without sugar) and sample A' is a sweetened cachaça, only sample A' was subjected to the modified QuEChERS process.

\section{Sample determination}

For the validation of the method, two samples of the same cachaça with (A') and without sugar (A) were supplied to us by a mixing and bottling industry in the region. In this way, QuEChERS were first applied to the samples with sugar, the two samples were analyzed by the method already developed by DI-ESI-MS and the result compared with the result of analysis by CG-MS carried out in a certified laboratory at the request of the industry.

To evaluate ethyl carbamate in real cachaça samples, it was purchased at a local supermarket eleven cachaça from different brands and prices. The brands were chosen because of their high acceptance by the local population. Among the eleven samples analyzed, only two had no sugar in their composition, as specified in the label. All these samples were analyzed using modified QuEChERS followed by determination using DI-ESI-MS/MS.

\section{Results and Discussion}

The conventional DI-ESI-MS/MS method developed by Ribeiro et al..$^{25}$ of ethyl carbamate determination was not efficient to evaluate sweetened cachaça or sweetened sugar 
cane spirit, due to the high degree of sugar that reveals a high matrix effect on the electrospray ionization source and the standard addition calibration method make the analyzes laborious and time-consuming. Considering that a variety of alcoholic beverages have sugar as additive and the need to improve the analytical frequency is always required, we developed a modified QuECheRS (the classic method uses primary and secondary amine, PSA, and our method just $\mathrm{K}_{2} \mathrm{CO}_{3}$ ) with an external calibration curve to analyze ethyl carbamate from these beverages..$^{25,26}$

\section{Modified QuEChERS}

Electrospray mass spectrometry analytical technique, without the use of chromatography usually results in the enhancement of the analytical frequency with the use of direct injection. However, there are issues when matrices are complex, sugar is known to harm ionization..$^{31}$ The formation of caramelized products in the cone reduces the ion entrance and may clog the orifice with a large number of injected samples. The residues of matrix compounds deposited on the cone can evaporate and react to ions ${ }^{32}$ or form supramolecular aggregates,$^{33}$ thereby reducing the ionic signal of the target molecules. Methodologies to reduce the matrix interference should be employed ${ }^{34}$ in order to improve response and also a better analytical frequency in the equipment (since complex matrices require frequent cleaning procedures).

The method developed by Catharino and co-workers, ${ }^{26}$ used the modified QuEChERS to reduce sucrose from the samples based on the addition of $\mathrm{K}_{2} \mathrm{CO}_{3}$ in the sample followed by stirring and phase separation and organic phase directly injected into the GC-MS system. The term modified QuEChERS refers to the lack of primary and secondary amine (PSA) that turns the method very cheap. Our methodology was developed for direct injection mass spectrometry with electrospray ionization technique, in this sense modifications were made to transform the modified QuEChERS adapted to our routine lab analyzes, then it was used $10 \mathrm{~g}$ of $\mathrm{K}_{2} \mathrm{CO}_{3}$ and $20 \mathrm{~mL}$ of sample with $2 \mathrm{~min}$ of vortexing. After phase separation, an $5 \mathrm{~mL}$ aliquot of the alcoholic phase was withdrawn, and added $60 \%$ of Milli-Q water to reconstruct the original proportion water:ethanol ratio with a final volume of $12.5 \mathrm{~mL}$, that was the proportion optimized for the mass spectrometer works for sugarless cachaças analyzes. ${ }^{26}$ Then, the sample was prepared as a regular unsweetened cachaça by DI-ESI-MS/MS using 18-crown-6/trifluoroacetic acid spiking additives as described by Ribeiro et al. ${ }^{25}$ We have reached the same mass spectrometer tuning as described by Ribeiro et al..$^{25}$ for sweetened cachaça, it has great advantage for routine analyzes, since all samples may be run in the same batch independently of sample preparation.

Table 1 shows the recovery (\%) for the sample preparation method applied to two real cachaças samples, sample A without added sucrose and sample A' with $30 \mathrm{~g} \mathrm{~L}^{-1}$ of sucrose added. The first column shows the results of the laboratory certified by MAPA to determine the concentration of ethyl carbamate in cachaça, the laboratory (government laboratory) used the GC-MS technique. The other columns show the results obtained from our laboratory method using the standard addition method. The real samples used to test the recoveries presented numbers close to $100 \%$, with relative standard deviations below $8.9 \%$ (Table 1). The extraction method using the modified QuEChERS showed no significant loss of ethyl carbamate signal over the extraction processes, demonstrating the efficiency of sugar elimination from the sample, and additionally, the ion suppression effect was well dealt during the sample preparation since the recovery was high. It was not observed carrying over for the DI-ESI-MS/MS analyzes. The method is currently used for routine analysis for quality control of a large cachaça industry and was successfully applied to evaluate the ethyl carbamate in commercial cachaça, and could be used together with GC-MS as a confirmatory test in Brazil for regulatory purposes independently of the sucrose added to the drink.

The intermediate precision was investigated by analyzing intra- and inter-day repeatability, and the calculated RSD values were in the range of 2.9 and $8.9 \%$, respectively. These values are in accordance with current resolutions for the determination of ethyl carbamate in sweetened cachaça. ${ }^{1}$

Figure 1 shows the standard addition of the sample analyzed by a certified laboratory, namely cachaça $\mathrm{A}$. The

Table 1. Ethyl carbamate contents in sample analyzed by certified laboratory of Brazilian sugar cane spirit and recovery using standard addition (Std add)

\begin{tabular}{|c|c|c|c|c|c|c|}
\hline $\begin{array}{l}\text { Previous analyzed } \\
\text { sample }^{\mathrm{a}}\left(\mu \mathrm{g} \mathrm{L}^{-1}\right)\end{array}$ & $\begin{array}{c}\text { Content (day 1)/ } \\
\left(\mu \mathrm{g} \mathrm{L}^{-1}\right)\end{array}$ & $\begin{array}{c}\text { Content (day 2) / } \\
\left(\mu \mathrm{g} \mathrm{L}^{-1}\right)\end{array}$ & $\begin{array}{c}\text { Mean }(\mathrm{n}=6) / \\
\left(\mu \mathrm{L} \mathrm{L}^{-1}\right)\end{array}$ & $\begin{array}{c}\mathrm{RSD}^{\mathrm{b}} \\
\text { (intra-day) / \% }\end{array}$ & $\begin{array}{c}\text { RSD } \\
\text { (inter-day) /\% }\end{array}$ & Recovery / \% \\
\hline Cachaça (A) $240 \mu \mathrm{g} \mathrm{L}^{-1}$ & 242.7 & 254.0 & 248.4 & 8.9 & 3.2 & 103.5 \\
\hline Cachaça (A') $226 \mu \mathrm{g} \mathrm{L}^{-1}$ & 229.1 & 248.6 & 238.9 & 2.9 & 5.8 & 105.7 \\
\hline
\end{tabular}

${ }^{a}$ Analyzed in governmental laboratory certified by MAPA; bay 1 . A: commercial sugar-free cachaça provided by the mixing and bottling industry in the region and A': commercial cachaça A with sugar; RSD: relative standard deviation. 
coefficient of determination was $\mathrm{R}^{2}=0.995$ and the linear regression $y=0.2585 x+56.339$. The value obtained for the concentration of ethyl carbamate was $242.7 \mu \mathrm{g} \mathrm{L}^{-1}$ (day 1) and the certification value was $240.0 \mu \mathrm{g} \mathrm{L}^{-1}$, a recovery percentage of $101.1 \%$.

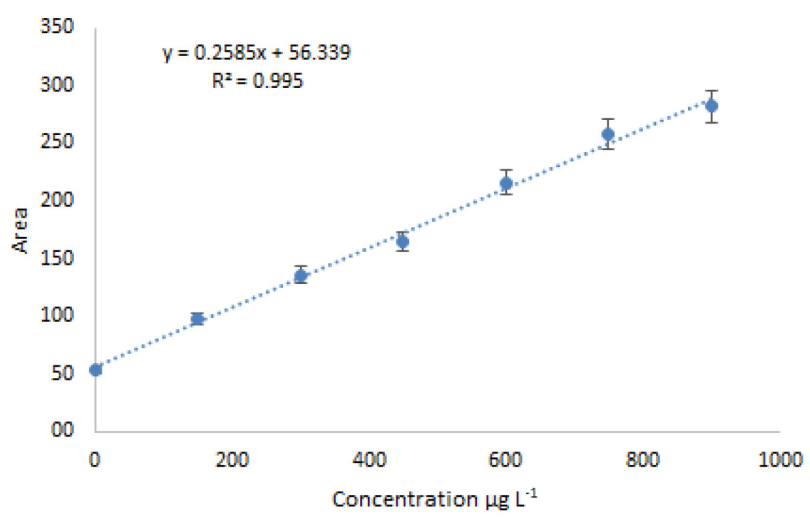

Figure 1. Peak areas of characteristic SRM channel $(90>62)$ of ethyl carbamate as a function of standard addition concentration for certified sample A of $240.0\left(\mu \mathrm{g} \mathrm{L}^{-1}\right)$ of ethyl carbamate. Note, the linear response $y=0.2585 x+56.339, \mathrm{R}^{2}=0.995$, which is maintained from the lowest concentration to the highest concentration.

The LOD and LOQ for the standard addition were determined as the concentration that gives the signal-to-noise ratio of 10:1 and 3:1, respectively, the LOQ and LOD obtained were 75.0 and $7.5 \mu \mathrm{g} \mathrm{L}^{-1}$, respectively. ${ }^{25}$ These values are adequate to analyzes of sweetened cachaça, since the limits defined by MAPA in a Brazilian Regulation Agency for Food Control are $210 \mu \mathrm{g} \mathrm{L}^{-1}{ }^{1}$

For the analyzes by standard addition, the limits of detection (LOD) and quantification (LOQ) were recalculated using the deviation of the linear coefficient and the slope. LOD and LOQ obtained were: 48.0 and $160.0 \mu \mathrm{g} \mathrm{L}^{-1}$ for cachaça A', respectively. Although the results obtained for LOD and LOQ are higher than the values obtained for some samples and even for the validation already developed, the results obtained by an external calibration curve corroborate the results obtained by standard addition both for certified samples and for commercial samples, with acceptable relative standard deviations (RSDs) according to the validation guides. ${ }^{29,35}$ Besides, the addition of sugar in cachaça may corroborate the increase in these parameters, since the use of the new method of preparation QuEChERS allows analysis, but does not guarantee that the sugar will be eliminated completely, thus increasing the baseline and the values of LOQ and LOD.

\section{Application to certified material and real samples}

Eleven real samples were prepared using QuEChERS modified in triplicate and analyzed by DI-ESI-MS/MS (Table 2). All samples were evaluated by standard addition and external analytical curve. Three real samples $(2,3$, and $7 ; 32.3,28.9$, and $62.3 \mu \mathrm{g} \mathrm{L}^{-1}$, respectively) with the lower ethyl carbamate found by standard addition were selected to be evaluated as external calibration curves. From the three calibration curves, cachaça 2 showed the lowest percentage of RSD, but cachaça 3 presented satisfactory results with all samples below $15 \%$ of the variation and one closer to $20 \%$. Table 2 presents that both methods showed good results since the RSD values were below $12.6 \%$ for the standard addition.

Table 2. Concentration of ethyl carbamate in sample of commercial cachaça. The extraction was made using QuEChERS modified and determination by DI-ESI-MS/MS. It was compared results for two sample determination: sample addition and calibration curve of linear regression of cachaças 2,3 and 7

\begin{tabular}{|c|c|c|c|c|c|c|c|c|}
\hline Sample & $\begin{array}{l}\text { Std add / } \\
\left(\mu \mathrm{g} \mathrm{L}^{-1}\right)\end{array}$ & $\begin{array}{l}\text { RSD Std } \\
\text { add } / \%\end{array}$ & $\begin{array}{l}\text { Ext cal curve } \\
\text { of cachaça } 2^{\mathrm{a}} / \\
\left(\mu \mathrm{g} \mathrm{L}^{-1}\right)\end{array}$ & $\begin{array}{l}\text { Ext cal curve } \\
\text { of cachaça } 3^{\mathrm{a}} / \\
\qquad\left(\mu \mathrm{g} \mathrm{L}^{-1}\right)\end{array}$ & $\begin{array}{l}\text { Ext cal curve } \\
\text { of cachaça } 7^{\mathrm{a}} / \\
\left(\mu \mathrm{g} \mathrm{L}^{-1}\right)\end{array}$ & $\begin{array}{l}\text { RSD Std add/Ext } \\
\text { cal of } 2\end{array}$ & $\begin{array}{l}\text { RSD Std add/Ext } \\
\text { cal of } 3\end{array}$ & $\begin{array}{l}\text { RSD Std add/Ext } \\
\text { cal of } 7\end{array}$ \\
\hline 1 & 362.3 & 8.2 & 365.8 & 399.3 & 306.3 & 0.7 & 6.8 & 11.8 \\
\hline 2 & 32.3 & 12.4 & 38.5 & 44.6 & 19.0 & 12.3 & 22.6 & 36.6 \\
\hline $3^{\mathrm{b}}$ & 28.9 & 10.1 & 25.0 & 29.9 & 7.0 & 10.2 & 2.4 & 86.2 \\
\hline $4^{b}$ & 73.9 & 3.4 & 65.7 & 74.0 & 42.8 & 8.3 & 0.1 & 37.7 \\
\hline 5 & 497.9 & 12.6 & 508.6 & 554.1 & 431.7 & 1.5 & 7.5 & 10.0 \\
\hline 6 & 286.6 & 3.8 & 312.9 & 341.9 & 259.8 & 6.2 & 12.4 & 6.9 \\
\hline 7 & 62.3 & 6.9 & 73.4 & 82.3 & 49.5 & 11.5 & 19.5 & 16.1 \\
\hline 8 & 501.9 & 12.4 & 511.8 & 557.6 & 434.5 & 1.4 & 7.4 & 10.1 \\
\hline 9 & 317.6 & 3.1 & 292.6 & 320.0 & 242.0 & 5.7 & 0.5 & 19.1 \\
\hline 10 & 235.0 & 5.5 & 256.4 & 280.8 & 210.3 & 6.1 & 12.5 & 7.8 \\
\hline 11 & 574.3 & 10.5 & 628.8 & 684.4 & 537.3 & 6.4 & 12.4 & 4.7 \\
\hline
\end{tabular}

Regression of cachaça 2: $y=0.2464 x+3.2591$; regression of cachaça 3: $y=0.2273 x+2.6936$; regression of cachaça $7: y=0.2806 x+7.0189$. ${ }^{\text {b } 3 \text { and } 4 \text { are }}$ sugar cane spirit without sugar. QuEChERS: quick, easy, cheap, effective, rugged, and safe; DI-ESI-MS/MS: direct injection electrospray tandem mass spectrometry; Std add: standard addition; Ext cal: external calibration. 
In addition, the LOQs and LODs were calculated for the three cachaças that were used as calibrants $(2,3$, and 7$)$ using the slope of external calibration curves. Cachaça 2, 3, and 7, showed LOD of 6.0, 7.0, $24.9 \mu \mathrm{g} \mathrm{L}^{-1}$, and LOQ of $20.0,23.3$, and $83.1 \mu \mathrm{g} \mathrm{L} \mathrm{L}^{-1}$, respectively. These results indicate that the method meets the criteria for the regulatory agency evaluation of cachaça of $210 \mu \mathrm{g} \mathrm{L}^{-1}$. The cachaças with the lower ethyl carbamate concentrations were those that obtained the best results and can be used as a calibrator for calculating the concentration of other cachaças, without the need to build a curve for each one as in the standard addition.

When comparing the two calibration methodologies, it appears that both presented good results, making it possible to use the external standard addition to replace the standard addition, since it has less analysis time and less solvent volume with acceptable RSD (\%). The results show how critical the presence of ethyl carbamate in sweetened cachaças produced in Brazil is an alarming number, since in some of them the value was above $500 \mu \mathrm{g} \mathrm{L}^{-1}$.

Furthermore, the proposed method proved to be highly efficient in relation to solvent consumption, since analysis without the use of chromatographic methods increases the analytical frequency. This can be seen in Table 3, which shows an average of the solvent used in our standard addition, ${ }^{25}$ external calibrations, and high-performance liquid chromatography (HPLC) analyzes. ${ }^{23}$ It can be seen that the use of our external standard addition methodology consumes a smaller amount of solvent than the standard addition and HPLC methodology.

Regarding the analytical frequency, the external calibration method is performed in a considerably shorter time than the standard addition method previously developed. ${ }^{25}$ To prepare eleven samples using the standard addition method takes about two hours, and each analysis two hours to be performed only once. On the other hand, in the analysis of the external calibration curve, the preparation takes about one hour and the analysis $40 \mathrm{~min}$. This proves that the use of the external calibration curve, in addition to consuming less solvent, is also faster than the previously developed method.

Table 3. Volume of solvent in different types of ethyl carbamate analysis in cachaças

\begin{tabular}{lc}
\hline Method & $\begin{array}{c}\text { Solvent volume for analysis } \\
\text { of } 10 \text { samples / mL }\end{array}$ \\
\hline Standard addition (DI-ESI-MS) & 120.0 \\
External calibration (DI-ESI-MS) $^{25}$ & 20.0 \\
External calibration (HPLC-FLD) $^{23}$ & 225.0 \\
\hline
\end{tabular}

DI-ESI-MS/MS: direct injection electrospray tandem mass spectrometry; HPLC-FLD: high-performance liquid chromatography with fluorescence detection.
The determination method proposed in the previous work ${ }^{25}$ had as a priority the quality control of cachaça that arrives from the production industry without sugar added. The focus of the present work was to evaluate the quality of cachaça that reaches the final consumer, i.e., with 6 or $30 \mathrm{~g} \mathrm{~L}^{-1}$. These results demonstrated that it was possible to obtain satisfactory results for sweetened cachaça using modified QuEChERS and DI-ESI-MS/MS determination with external or standard addition, with low environmental impact. The HPLC-MS/MS method for ethyl carbamate in soy sauce used around $15.5 \mathrm{~mL}$ of acetonitrile in each sample, ${ }^{36}$ while our method used $2 \mathrm{~mL}$ of methanol in each sample. The next step is to evaluate the presence of ethyl carbamate in other kinds of sweetened alcoholic beverages.

\section{Conclusions}

A DI-ESI-MS/MS method using modified QuEChERS was developed and validated for ethyl carbamate determination in sweetened cachaça. The results for linearity, recovery, and precision (intra- and inter-day) indicate that the method developed in this study was suitable for the determination of ethyl carbamate in matrices containing sucrose in their composition, specifically in Brazilian cachaça. The described method proved to be fast, with five min for sample preparation and one minute for DI-ESI-MS/MS for each sample. The LOD and LOQ of the assay are sufficient to control the presence of ethyl carbamate according to the MAPA guides, establishing a maximum value of $210 \mu \mathrm{g} \mathrm{L} \mathrm{L}^{-1}$. Solvent reduction reflected environmental impact concerns and the use of $2 \mathrm{~mL}$ of methanol in each sample was one of the differentials of this method.

\section{Acknowledgments}

The authors are grateful to Waters Company, Jamel Company, Forquimica Agroscience, Capes, CNPq, UEM and UFPR for the financial support.

\section{Author Contributions}

Angélica P. P. Tonin performed the experiments; Camila B. Poliseli, Nayane B. M. Sinosaki and Fernanda C. Martinez participated in the development of methodology and formatted the article; Oscar O. Santos, Cláudio C. Oliveira, Valquiria M. Silva, Jesui V. Visentainer and Eduardo C. Meurer supervised the work and discussed the idea and the applications; Eduardo C. Meurer, Valquiria M. Silva and Angélica P. P. Tonin wrote the article; Angélica P. P. Tonin and Eduardo C. Meurer had the main idea. All authors discussed the results and contributed to the final manuscript. 


\section{References}

1. Ministério da Agricultura, Pecuária e Abastecimento (MAPA); Instrução Normativa No. 28, de Agosto de 2014, available at http://www.gov.br/agricultura/pt-br/assuntos/inspecao/ produtos-vegetal/legislacao-1/biblioteca-de-normas-vinhos-ebebidas/instrucao-normativa-no-28-de-8-de-agosto-de-2014. pdf/view, accessed in December 2021.

2. Ministério da Agricultura, Pecuária e Abastecimento (MAPA); Instrução Normativa No. 13, de 29 de Junho de 2005, Aprova o Regulamento Técnico para Fixação dos Padrões de Identidade e Qualidade para Aguardente de Cana e para Cachaça, available at http://www.gov.br/agricultura/pt-br/assuntos/inspecao/ produtos-vegetal/legislacao-1/biblioteca-de-normas-vinhos-ebebidas/instrucao-normativa-no-13-de-29-de-junho-de-2005. pdf/view, accessed in December 2021.

3. Riachi, L. G.; Santos, A.; Moreira, R. F. A.; de Maria, C. A. B.; Food Chem. 2014, 149, 159.

4. Franco, M. O. K.; Suarez, W. T.; Santos, V. B.; Food Anal. Methods 2017, 10, 508.

5. Pessoa, K. D.; Suarez, W. T.; dos Reis, M. F.; Franco, M. O. K.; Moreira, R. P. L.; dos Santos, V. B.; Spectrochim. Acta, Part A 2017, 18,310

6. Zimmerli, B.; Schlatter, J.; Mutat. Res. 1991, 259, 325.

7. Baffa Jr., J. C.; Mendona, R. C. S.; Pereira, J. M. A. T. K.; Pereira, J. A. M.; Soares, N. F. F.; Food Chem. 2011, 129, 1383.

8. Ryu, D.; Choi, B.; Kim, N.; Koh, E.; Food Chem. 2016, 211, 770.

9. Chen, D.; Ren, Y.; Zhong, Q.; Shao, Y.; Zhao, Y.; Wu, Y.; Food Chem. 2017, 72, 283.

10. Li, G.; Zhong, Q.; Wang, D.; Zhang, X.; Gao, H.; Shen, S.; Food Control 2015, 56, 169.

11. Nanita, S. C.; Kaldon, L. G.; Anal. Bioanal. Chem. 2016, 408, 23.

12. Fenn, J. B.; Mann, M.; Meng, C. K.; Wong, S. F.; Whitehouse, C. M.; Science 1989, 246, 44.

13. Sarvin, B.; Lagziel, S.; Sarvin, N.; Mukha, D.; Kumar, P.; Aizenshtein, E.; Shlomi, T.; Nat. Commun. 2020, 11, 3186.

14. Costa, F. F.; Brand, G. D.; Grobério, T. S.; Braga, J. W. B.; Zacca, J. J.; Microchem. J. 2019, 147, 1123.

15. Sinosaki, N. B. M.; Tonin, A. P. P.; Ribeiro, M. A. S.; Poliseli, C. B.; Roberto, S. B.; da Silveira, R.; Visentainer, J. V.; Santos, O. O.; Meurer, E. C.; J. Braz. Chem. Soc. 2020, 31, 402.

16. Tonin, A. P. P.; Ribeiro, M. A. S.; Poliseli, C. B.; da Silveira, R.; Visentainer, J. V.; Silva, V. M.; Ribeiro, L. F.; de Souza, R. C. T.; de Oliveira, C. C.; Meurer, E. C.; J. Braz. Chem. Soc. 2019, 30, 350

17. Poliseli, C. B.; Ribeiro, M.; Tonin, A. P. P.; Vagula, J. M.; Santos, O. O.; Visentainer, J. V.; Pontes, R. M.; Moraes, L. A. B.; Meurer, E. C.; J. Mass Spectrom. 2018, 53, 1230.

18. Okada, E.; Coggan, T.; Anumo, T.; Clarke, B.; Allinson, G.; Anal. Bioanal. Chem. 2019, 411, 715.
19. Longo, E.; Morozova, K.; Yenera, S.; Bosellia, E.; Biasioli, F.; Scampicchio, M.; J. Mass Spectrom. 2019, 54, 412.

20. Khanal, D. D.; Baghdady, Y. Z.; Figard, B. J.; Schug, K. A.; Rapid Commun. Mass Spectrom. 2019, 33, 821.

21. Marín-Sáez, J.; Romero-González, R.; Frenich, A. G.; Food Chem. 2019, 275, 746.

22. Vicentim, M. P.; Monteiro, T. M.; Almeida, R. R. R.; Soares, A. D. A.; Rodrigues, J. M.; Rego, E. C. P.; Microchem. J. 2019, 197, 497.

23. Machado, A. M. D. R.; Cardoso, M. D. G.; Saczk, A. A.; Anjos, J. P.; Emídio, E. S.; Zacaroni, L. M.; Dorea, H. S.; Nelson, D. L.; Food Chem. 2013, 138, 1233.

24. Lachenmeier, D. W.; Frank, W.; Kuballa, T.; Rapid Commun. Mass Spectrom. 2005, 19, 108.

25. Ribeiro, M. A.; Tonin, A. P. P.; Poliseli, C. B.; Oliveira, C. C.; Visentainer, J. V.; Silva, V. M.; Meurer, E. C.; Food Anal. Methods 2019, 12, 69.

26. Guerreiro, T. M.; Ozawa, K. S.; Lima, E. O.; Melo, C. F. O. R.; Oliveira, D. N.; Triano, S. P. N.; Catharino, R. R.; Front. Nutr. 2018, 5, 21 .

27. Tonin, A. P. P.; Ribeiro, M. A. S.; Silva, V. M.; Oliveira, C. C.; Saragiotto, M. H.; Eberlin, M. N.; Meurer, E. C.; Int. J. Mass Spectrom. 2017, 418, 37.

28. Compton, B. J.; Siuzdak, G.; Spectroscopy 2003, 17, 699.

29. Food and Agriculture Organization of the United Nations (FAO); Validation of Analytical Methods for Food Control; FAO: Vienna, 1997, available at http://www.fao.org/publications/card/ en/c/b5844220-5184-57bd-b861-9c5bc013ad4b, accessed in December 2021

30. Bauer, L. C.; Santana, D. A.; Macedo, M. S.; Torres, A. G.; de Souza, N. E.; Simionato, J. I.; J. Braz. Chem. Soc. 2014, 25, 161.

31. Antignac, J.-P.; Wasch, K.; Monteau, F.; de Brabander, H.; François, A.; le Bizec, B.; Anal. Chim. Acta 2005, 529, 129.

32. Meurer, E. C.; Sabino, A. A.; Eberlin, M. N.; Anal. Chem. 2003, 75,4701

33. Bongiorno, D.; Ceraulo, L.; Giorgi, G.; Indelicato, S.; Ruggirelloc, A.; Liveric, V. T.; Eur. J. Mass Spectrom. 2009, $16,151$.

34. Cortese, M.; Gigliobianco, M. R.; Magnoni, F.; Censi, R.; Martino, P. D.; Molecules 2020, 25, 3047.

35. Food and Drug Administration (FDA); Guide for Industry, Bioanalytical Method Validation, available at http://www.fda. gov/regulatory-information/search-fda-guidance-documents/ bioanalytical-method-validation-guidance-industry, accessed in December 2021.

36. Park, S.-K.; Kim, C. T.; Lee, J.-W.; Jhee, O. H.; Om, A. S.; Kang, J. S.; Moon, T. W.; Food Control 2007, 18, 975.

Submitted: April 30, 2021

Published online: January 5, 2022 